\title{
Grazing systems for year-round beef production
}

\author{
CP Bagley 1, DG Morrison 2 \\ 'North Mississippi Research and Extension Center Verona, MS 38879 ; \\ 2Rosepine Research Station, Rosepine, LA 70659, USA
}

\begin{abstract}
A study was undertaken to evaluate the production of slaughter weight beef grazing pastures to estimate productive efficiency and economic feasibility of forage-based systems. Grazed forages were used as the primary nutrient source for calves from both fall and spring cow-calf management systems. Steers were to attain slaughter weights for six times at 2 mo intervals throughout the year. During the final $120 \mathrm{~d}$, cattle were either grazed or fed a corn silage based diet.
\end{abstract}

Fall-born calves were randomly assigned to groups 1, 2 or 3 and spring-born calves randomly assigned to groups 4,5 or 6 . Cattle were managed in an attempt to reach a target minimum weight of $455 \mathrm{~kg}$ at an age of 17,19 , $21,19,21$ and $23 \mathrm{mo}$, respectively. The preferred grazed forage mixture for cattle during November to May was ryegrass-clover. Forages during the remainder of the year were bermudagrass-clover or summer annuals. During periods of limited forage availability, steers closest to final termination were given forage preference over younger cattle.

Steer gains were greatest while grazing ryegrass-clover pastures, and lowest while grazing pastures during the middle of summer. In general, high animal performance resulted in a lower cost $/ \mathrm{kg}$ of gain. The time $(\mathrm{mo})$ between trial initiation until slaughter ranged from 8 to $14 \mathrm{mo}$. Cost $/ \mathrm{kg}$ of gain were similar for all outcome groups, ranging from $\$ 1.05-\$ 1.21 / \mathrm{kg}$ (US \$). Steers fed corn silage the final $4 \mathrm{mo}$ had higher rates of gain $(0.98$ vs $0.76 \mathrm{~kg} / \mathrm{d}$; $P<0.05)$, but a higher cost $/ \mathrm{kg}$ of gain ( $\$ 1.52$ vs $\$ 1.14$ ) compared to forage-finished steers, respectively.

Carcass characteristics for cattle finished the final 4 mo on corn silage diets had greater $(P<0.05)$ dressing percentage, heavier carcass weights, higher marbling scores, higher quality grades, whiter external fat and a greater amount of backfat thickness than did forage finished steers.

In conclusion, forage systems can be developed and managed which can produce a year-round supply of finished beef using forages as the primary nutrient source. Animal performance was greatest during cooler times of the year, and lowest during the hotter times of the year, regardless of whether cattle were fed corn silage or forages. 